\title{
PENGARUH LATIHAN PUSH-UP DAN PULL - UP TERHADAP KEKUATAN OTOT LENGAN PADA ATLET PANAHAN PERPANI KABUPATEN BANJAR
}

\author{
Saparuddin \\ Universitas Lambung Mangkurat \\ dikupas@yahoo.co,id
}

\begin{abstract}
Abstrak
Penelitian ini bertujuan untuk mengetahui pengaruh latihan push up dan pull up terhadap kekuatan otot lengan pada atlet panahan perpani Kabupaten Banjar. Metode penelitian yang digunakan dalam penelitian ini adalah metode Experimental. Desain penelitian adalah Two Group Pretest-Posttest,. Populasi dalam penelitian ini adalah atlet panahan perpani Kabupaten Banjar berjumlah 8 orang, sedangkan yang menjadi sampel dalam penelitian semua anggota populasi dijadikan sampel sebanyak 8 dengan teknik pengambilan sampel menggunakan teknik Sampling jenuh.

Hasil penelitian menunjukan bahwa pemberian latihan pada kedua kelompok yaitu kelompok push up dan kelompok pull up selama 16 kali pertemuan atau 8 minggu ada peningkatan . Hal ini terbukti dari rata-rata masing-masing test mendorong dan menarik dynamometer kelompok push-up sebagai berikut tes awal mendorong adalah 15,00, tes akhir mendorong dynamometer 18,00, tes awal mendorong dynamometer adalah 16,00 dan tes akhir menarik dynamometer 18,25, Hasil analisis data deskriptif menujukkan adanya peningkatan nilai hasil pengukuran setelah diberikan perlakukan push-up. Untuk nilai rata-rata test mendorong dan menarik dynamometer kelompok pull-up tes awal mendorong adalah 14,75 , tes akhir mendorong dynamometer 17,25, tes awal menarik dynamometer adalah 16,25 dan tes akhir menarik dynamometer 20,50. Hasil analisis data deskriptif menujukkan adanya peningkatan nilai hasil pengukuran setelah diberikan perlakukan pull-up.

Hasil analisis Sig. (2-tailed) tes awal-tes akhir mendorong dynamomter 0,356>0,05, karena hasil Sig. (2-tailed) sebesar 0,356 lebih besar dari 0,05 maka tidak terdapat perbedaan pengaruh yang signifikan rata-rata pada sebelum dan sesudah perlakuan pada kelompok push-up dan pull-up. Sedangkan hasil Sig. (2-tailed) tes awal dan tes akhir menarik dynamometer sebesar 0,025<0,05 karena hasil Sig. (2tailed) sebesar 0,025 lebih kecil dari 0,05, maka terdapat perbedaan pengaruh yang signifikan rata-rata sebelum dan sesudah perlakuan pada kelompok push-up dan pull-up.

Kesimpulannya hasil penelitian ini adalah 1) ada pengaruh yang signifikan latihan push up terhadap kekuatan otot lengan pada atlet panahan perpani Kabupaten Banjar. 2) ada pengaruh yang signifikan latihan push up dan pull up terhadap kekuatan otot lengan pada atlet panahan perpani Kabupaten Banjar. 3) ada perbedaan pengaruh yang signifikan latihan push up dan pull up terhadap kekuatan otot lengan pada atlet panahan perpani Kabupaten Banjar.
\end{abstract}

Kata kunci: Pengaruh Latihan push-up, pul- up Panahan, Perpani, Kekuatan Otot lengan

\section{Abstract}

This study aims to determine the effect of push-up and pull-up exercises on arm muscle strength in the Banjar archery athletes in Banjar Regency. The research method used in this study is the experimental method. The research design was Two Group Pretest-Posttest,. The population in this study were 8 archives in Banjar regency, while the sample in this study all population members were sampled as many as 8 by the sampling technique using saturated sampling technique.

The results showed that the provision of exercise in both groups namely the push-up group and the pull-up group for 16 meetings or 8 weeks there was an increase. This is evident from the average of each push and pull test of the dynamometer push-up group as follows the initial push test is 15.00, the final test pushes the dynamometer 18.00, the initial test pushes the dynamometer is 16.00 and the final test pulls the dynamometer 18.25, The results of descriptive data analysis show an increase in the value of the measurement results after being given a push-up treatment. For the average value of the push and pull test dynamometer, the pull-up group of the initial push test is 14.75, the final test pushes the dynamometer 17.25, the initial test pulls the dynamometer is 16.25 and the final test pulls the 
dynamometer 20.50. The results of the descriptive data analysis showed an increase in the value of the measurement results after being treated with pull-ups.

The results of the analysis of Sig. (2-tailed) initial-final test encourages dynamomter 0.356> 0.05 , because of the results of Sig. (2-tailed) of 0.356 is greater than 0.05, there is no significant difference in the average effect before and after treatment in the push-up and pull-up groups. While the results of Sig. (2-tailed) initial test and final test draw dynamometer of $0.025<0.05$ because of the results of Sig. (2-tailed) of 0.025 is smaller than 0.05, there is a significant difference in the average effect before and after treatment in the push-up and pull-up groups.

In conclusion, the results of this study are: 1) there is a significant effect of push up exercises on arm muscle strength in Banjani Regency archery athletes. 2) there is a significant effect of push-up and pull-up exercises on arm muscle strength in the Banjar archery athletes in Banjar Regency. 3) there is a significant difference in the effect of push-up and pull-up exercises on arm muscle strength in Banjar district archipelago athletes.

Key Words :Effects of Push-up Exercises, Archery Pulses, Perpani, Arm Muscle Strength.

Dipublikasikan Oleh : 


\section{PENDAHULUAN}

Cabang olahraga panahan merupakan gabungan antara olahraga dan seni. Disebut olahraga karena menggunakan otot-otot fungsional, seperti trapezius, tricep dan deltoid serta juga membutuhkan daya tahan fisik. Disebut seni karena membutuhkan sentuhan jiwa yang halus, kesabaran, keuletan dan ketahanan mental (Nukhrawi Nawir, 2011 :123). Selanjutnya olahraga panahan ditinjau dari keterampilan motorik dapat dibagi menjadi dua yaitu: "(a) keterampilan motorik kasar (gross motor skills) dan (b) keterampilan motorik halus (fine motor skills)". (Singer, dikutip Winarno, 1995:23-24). Dalam pandangan lain sebagaimana dijelaskan Winarno, (1995:24) dalam bukunya belajar motorik, bahwa keterampilan motorik halus adalah "keterampilan gerak yang melibatkan otot-otot halus sebagai penggerak utama. Sebagai contoh keterampilan menarik pelatuk senapan, keterampilan melepas anak panah pada cabang olahraga panahan".

Keterampilan gerak halus menurut pendapat diatas yaitu melibatkan otot-otot kecil terutama jari-jari dan lengan bagian bawah sedangkan keterampilan motorik kasar adalah keterampilan motorik yang melibatkan aktivitas otot yang besar, seperti menggerakan lengan tangan.

Unsur pendukung keterampilan gerak dalam olahraga ditinjau dari unsur fisik diantaranya daya tahan, fleksibilitas, kekuatan, kecepatan, ketajaman indera, dan kecepatan waktu reaksi. Keterampilan gerak lain yang saling turut mempengaruhi yaitu komponen fisik, mental, konsentrasi, visualisasi dan teknik.

Menurut Susanto, (2015:189), bahwa : "Komponen fisik yang diperlukan dalam olahraga panahan antara lain: (1) kondisi fisik, (2), kekuatan otot (3) daya tahan otot dan (4) teknik.

Selain itu ada beberapa komponen lain yang mempengaruhi olahraga panahan yaitu: konsentrasi, dan visualisasi

Kemampuan kondisi fisik, kekuatan otot lengan serta teknik yang baik sangat membantu dalam membidik sasaran (target face) pada olahraga panahan.

Teknik dasar dominan menahan busur (holding) adalah :"dilakukan dengan menggunakan otot-otot lengan tidak dibantu oleh badan....pemanah harus tetap berkonsentrasi agar sikap memanah tidak berubah merupakan garis lurus memanah". (I Wayan Artanayasa, 2014 : 20).

Otot-otot yang paling mendasari untuk menahan dan menarik busur panah adalah komponen fisik kekuatan otot lengan dan daya tahan otot lengan dan bahu. Harsono (2004) dikutip Fitri Rahma Yenni,dkk, (2012:3), menjelaskan bahwa : "Otot - otot yang paling penting dan spesifik diperlukan untuk menarik dan menahan berat tarikan busur ialah otot - otot jari trapezius, bisep, rhomboid, deltoid, dan trisep".

Berdasarkan hasil observasi di Perpani Kabupaten Banjar pada saat latihan bulan Desember 2017 di Lapangan SMA 2 Martapura Kabupaten Banjar, kenyataannya pemanah tidak mampu mendorong dan menarik busur, hal ini dari beberapa atlet ada juga yang tidak cukup melepaskan 6 anak panah dalam 1 rambahan (babak untuk setiap jarak).

Dengan demikian kekuatan otot lengan dan bahu pada atlet panahan perpani Kabupaten Banjar saat menarik beratnya tali busur masih sangat lemah dan kurang. Lemahnya kekuatan otot lengan dan bahu menarik dan mendorong busur disebabkan kurangnya latihan fisik seperti latihan push-up dan pullup tidak dilakukan secara intensif oleh atlet panahan Perpani Kabupaten Banjar. Hal ini push-up dan pullup turut sangat mempengaruhi kemampuan saat melakukan menarik dan mendorong busur panah.

Agar tidak terjadi pembiaran terhadap kondisi kurangnya kekuatan otot lengan dalam menarik beratnya tali busur dan mendorong busur panahan tersebut, maka perlu dilakukan pengkajian secara mendalam terhadap kekuatan otot lengan dengan dimaksimalkannya bentuk latihan yaitu push-up dan pull-up, karena push-up dan pull-up merupakan latihan yang menggunakan gerakan menarik dan mendorong dengan otot lengan.

"Push-up merupakan salah satu latihan beban yang sangat baik dan efektif karena melibatkan otot-otot lengan dan bahu (deltoid, trisep, biseps,brakioradialis".(Gede Aryana, 2012:7).

"Sebagai satu bentuk latihan kekuatan,latihan pull-up merupakan bentuk latihan yang tepat bagi peningkatan otot lengan".(Enjang,2018:57).

Berdasarkan pendapat tersebut diatas bahwa push-up dan pull-up adalah salah satu bentuk latihan fisik, yang bertujuan untuk melatih unsur kekuatan otot lengan dan bahu, karena pada saat melakukan push-up dan pull-up beberapa otot tubuh pada bagian bahu depan, dada dan lengan akan bekerja sangat kuat.

Latihan push-up dan pull-up akan menjadi variabel indenpenden yang akan diuji pengaruhnya terhadap kekuatan otot lengan. Dengan demikian tujuan umum penelitian ini adalah untuk mengetahui 
jenis latihan yang paling efektif untuk meningkatkan kualitas kekuatan otot lengan pada atlet panahan Perpani Kabupaten Banjar.

\section{METODE}

Penelitian ini menggunakan metode Esksperimental Design dengan desain Two-Group PretestPosttest. "Pada desain ini terdapat prestest sebelum diberi perlakuan dan posttest sesudah diberi perlakuan. Sampel penelitian ini hanya menggunakan sampel berjenis kelamin laki-laki berjumlah 8 orang,dengan teknik sampling jenuh. Instrumen tes yang digunakan dalam penelitian ini adalah push dan pull dynamometer. " Tujuannya untuk mengukur kekuatan otot lokal (kekuatan otot lengan) dalam menarik dan mendorong. Langkah-langkah pengumpulan data penelitian ini sebagai berikut : 1)Tahap persiapan pengumpulan data 2)Tahap pelaksanaan pengambilan data.

\section{HASIL DAN PEMBAHASAN}

1. Hasil penelitian analisis statistik deskriptif sebagai berikut :

Tabel 1. Analisis statistik deskriptif tes awal dan tes akhir mendorong menarik dynamometer), kelompok push-up

\begin{tabular}{|c|l|c|c|c|c|}
\hline \multirow{2}{*}{ No } & \multirow{2}{*}{ Tendensi Sentral } & \multicolumn{2}{|c|}{ Tes Mendorong } & \multicolumn{2}{c|}{ Tes Menarik } \\
\cline { 3 - 5 } & & Awal & Akhir & Awal & Akhir \\
\hline 1 & N & 4 & 4 & 4 & 4 \\
\hline 2 & Mean & 15,00 & 18,00 & 16,00 & 18,25 \\
\hline 3 & Standar Deviasi & 1,633 & 1,826 & 2,449 & 2,500 \\
\hline 4 & Varians & 2,667 & 3,333 & 6,000 & 6,250 \\
\hline 5 & Skor tertinggi & 17 & 20 & 19 & 21 \\
\hline 6 & Skor terendah & 13 & 16 & 13 & 15 \\
\hline
\end{tabular}

Berdasarkan tabel 1 tersebut diatas hasil analisis deskriptif dapat diuraikan sebagai berikut : untuk data tes mendorong dan menarik dynamometer, dari 4 jumlah sampel kelompok push up diperoleh hasil tes awal mendorong dynamometer tertinggi 17 dan terendah 13. Tes akhir mendorong dynamometer hasil 20 dan terendah 16.

Sedangkan hasil tes tes awal menarik dynamometer diperoleh hasil tertinggi 19 dan terendah 13. Tes akhir menarik dynamometer diperoleh hasil tertinggi 21 dan terendah 15. Rata-rata (mean) masingmasing test mendorong dan menarik dynamometer antara lain tes awal mendorong adalah 15,00, tes akhir mendorong dynamometer 18,00, tes awal mendorong dynamometer adalah 16,00 dan tes akhir menarik dynamometer 18,25, sedangkan standar deviasi tes awal mendorong dynamometer adalah 1,633, tes akhir mendorong dynamometer 1,826, tes awal menarik dynamometer adalah 2,449 dan tes akhir menarik dynamometer 2,500. Hasil analisis data deskriptif menujukkan adanya peningkatan nilai hasil pengukuran setelah diberikan perlakukan push-up.

Tabel 2. Analisis statistik deskriptif tes awal dan tes akhir mendorong menarik dynamometer), kelompok

\begin{tabular}{|c|l|c|c|c|c|}
\multicolumn{2}{|c|}{ pull-up } & \multicolumn{2}{c|}{ Tes Mendorong } & \multicolumn{2}{c|}{ Tes Menarik } \\
\cline { 3 - 6 } No & & Awal & Akhir & Awal & Akhir \\
\hline 1 & N & 4 & 4 & 4 & 4 \\
\hline 2 & Mean & 14,75 & 17,25 & 16,25 & 20,50 \\
\hline 3 & Standar Deviasi & 1,708 & 1,258 & 1,500 & 1,291 \\
\hline 4 & Varians & 2,917 & 1,583 & 2,250 & 1,667 \\
\hline 5 & Skor tertinggi & 17 & 19 & 18 & 22 \\
\hline 6 & Skor terendah & 13 & 16 & 15 & 19 \\
\hline
\end{tabular}

Berdasarkan tabel 2 tersebut diatas hasil analisis deskriptif dapat diuraikan sebagai berikut : untuk data tes mendorong dan menarik dynamometer, dari 4 jumlah sampel kelompok pull-up diperoleh 
hasil tes awal mendorong dynamometer tertinggi 17 dan terendah 13. Tes akhir mendorong dynamometer hasil 19 dan terendah 16.

Sedangkan hasil tes tes awal menarik dynamometer diperoleh hasil tertinggi 18 dan terendah 15 . Tes akhir menarik dynamometer diperoleh hasil tertinggi 22 dan terendah 19. Rata-rata (mean) masingmasing test mendorong dan menarik dynamometer antara lain tes awal mendorong adalah 14,75 , tes akhir mendorong dynamometer 17,25, tes awal mendorong dynamometer adalah 16,25 dan tes akhir menarik dynamometer 20,50, sedangkan standar deviasi tes awal mendorong dynamometer adalah 1,708, tes akhir mendorong dynamometer 1,258 , tes awal menarik dynamometer adalah 1,500 dan tes akhir menarik dynamometer 1,291. Hasil analisis data deskriptif menujukkan adanya peningkatan nilai hasil pengukuran setelah diberikan perlakukan pull-up.

Sebagaimana hasil analisis Analisis statistik deskriptif tersebut diatas menunjukkan bahwa latihan pullup lebih baik dan efektif dibandingkan dengan latihan push-up dalam meningkatkan kekuatan otot lengan khususnya dalam menarik tali busur panahan.

Panahan merupakan cabang olahraga yang sangat memerlukan kekuatan otot, koordinasi, daya tahan, kelentukan, panjang tarikan, dan keseimbangan untuk membentuk teknik memanah yang baik. Faktor-faktor di atas haruslah ditunjang dengan latihan yang baik serta kondisi fisik yang prima dan tahan lama. Kondisi fisik yang dimaksud disini yaitu bahwa seorang pemanah tidak hanya sekedar memiliki daya tahan, kelentukan koordinasi, panjangnya tarikan tali busur, tetapi juga harus didukung oleh kekuatan yang besar agar penampilan si atlet tersebut tidak hanya bagus pada awal perlombaan saja, tetapi konsisten sampai akhir perlombaan.

Kondisi fisik kekuatan otot lengan dapat dilatih dengan latihan push-up dan pull-up secara spesifik otot yang terlibat dalam gerakan push-up diantaranya otot biceps,triceps, trapezius, palmaris longus, dan flexor carpi radialis. Demikian juga dengan otot yang sangat berperan dalam latihan pull-up diantaranya otot biceps brachii, triceps brachii, deltoids, trapezius, flexor digitorum superfialis, brachioradialis, palmaris longus,flexor carpi radialis dan flexor carpi ulnaris. Harsono (2004) dikutip Fitri Rahma Yenni,dkk, (2012:3), menjelaskan bahwa : "Otot - otot yang paling penting dan spesifik diperlukan untuk menarik dan menahan berat tarikan busur ialah otot - otot jari trapezius, bisep, rhomboid, deltoid, dan trisep"

Gerakan menarik beratnya tali busur pada olahraga panahan kelompok otot yang berperan adalah otot trapezius, tricep, biceps, deltoid, otot latissimus dorsi, flexor digitorum superfialis, brachioradialis, palmaris longus,flexor carpi radialis dan flexor carpi ulnaris.

Dalam perlakuan metode latihan push-up dan pull-up dimanipulasi dengan metode latihan kekuatan yang tujukan pada kelompok otot tersebut diatas dengan harapan ada adaptasi hasil manipulasi yang akibatnya kekuatan otot lengan menjadi lebih meningkat. Nukhrawi Nawir (2011:124) menjelaskan bahwa "Kekuatan otot lengan adalah kekuatan yang dihasilkan oleh otot-otot lengan yang bergerak sesuai dengan derajat kebebasan yang dimilikinya".

Kekuatan otot lengan adalah kemampuan seseorang untuk mengeluarkan tenaga secara maksimal dalam satu usaha, sesuai dengan prinsip-prinsip latihan yang diterapkan dalam penelitian ini.

Prinsip-prinsip latihan dalam penerapan pelaksanaan latihan push-up dan pull-up, diantaranya prinsip perbedaan individul artinya bahwa setiap individu sampel berbeda kemampuannya sehingga intensitas dan repetisi latihan yang dilakukan berbeda, dengan memperhatikan faktor-faktor yang mempengaruhi seperti keturunan, gizi, waktu istirahat, rasa sakit dan cidera, tingkat kebugaran, kematangan, motivasi, dan lingkungan.

Prinsip latihan peningkatan/kemajuan didasari oleh kegiatan latihan yang sistimatis artinya dari yang mudah ke yang sukar atau dari yang sederhana ke yang kompleks, dari latihan yang ringan ke latihan berat, secara bertahap menambah intensitas, set dan repetisi latihan.

Prinsip variasi yang dilakukan agar tidak terjadi kejenuhan ataupun kelelahan, maka latihan selalu bervariatif agar sampel tidak merasa bosan seperti mengubah bentuk latihan, berpindah tempat dengan sarana dan prasarana latihan yang sederhana.

Prinsip-prinsip latihan tersebut diatas diaplikasikan pada sampel dengan pemberian perlakuan latihan push-up dan pull up menunjukkan bahwa kemampuan kekuatan otot lengan meningkat terbukti dari hasil tes awal dan tes akhir setelah diberikan perlakuan, hasil rata-rata sebelum dan sesudah diberi latihan push-up hasil tes awal mendorong adalah 15,00, tes akhir mendorong dynamometer 18,00, tes awal menarik dynamometer adalah 16,00 dan tes akhir menarik dynamometer 18,25. Sedangkan rata-rata 
sebelum dan sesudah diberi latihan pull-up hasil tes awal mendorong adalah 14,75 , tes akhir mendorong dynamometer 17,25, tes awal menarik dynamometer adalah 16,25 dan tes akhir menarik dynamometer 20,50 hal ini menujukkan latihan pull-up lebih baik dan efektif dalam meningkatkan kekuatan otot lengan.

Kekuatan otot lengan merupakan unsur dominan dalam cabang olahraga panahan, untuk meningkatkan kekuatan otot lengan peneliti melakukan perlakuan latihan push-up dan pull-up, seperti dilakukan Gede Aryana (2012) dalam penelitiannya berjudul pengaruh pelatihan push-up terhadap peningkatan kekuatan menarik dan mendorong otot lengan.

Relevansinya penelitian tersebut dengan penelitian ini ada upaya atau usaha dalam peningkatan kemampuan kekuatan otot lengan, namun peningkatan kekuatan otot lengan khususnya menarik beratnya tali busur akan lebih baik dan efektif hasilnya apabila menerapkan metode latihan kekuatan otot lengan dengan materi latihan pull-up, karena gerakan pull-up sangat tepat untuk gerakan menarik beratnya tali busur agar lengan tidak terjadi gemetar.

Namun demikian pada prinsipnya bahwa latihan push-up dan pull-up merupakan bentuk latihan yang mampu memberikan suatu sumbangsi positif yang dapat mengarahkan atlet untuk memacu diri baik dari segi peningkatan latihan fisik, teknik maupun dalam mencapai keterampilan dalam memanah.

Karena kekurangan dan keterbatasan wawasan peneliti sudah tentu masih banyak persoalan yang harus akan diperbaiki jika akan melakukan penelitian yang sejenis diwaktu dan kesempatan yang lain. Dengan demikian jelaslah bahwa meningkatnya kekuatan otot lengan yang diperoleh masing-masing individu atlet panahan Perpani Kabupaten Banjar mutlak didapat dari usaha individu atlet itu sendiri yang selalu mendapat bimbingan latihan dari peneliti yaitu melalui program latihan push-up dan pull-up secara terus menerus selama 8 (delapan) minggu atau 16 (enam belas) kali pertemuan sehingga peningkatan kekuatan otot lengan atlet panahan dapat tercapai.

\section{PENUTUP}

\section{Kesimpulan}

Berdasarkan hasil pengujian analisis data yang diperoleh dan pembahasan hasil penelitian maka dapat disimpulkan bahwa : 1) Ada pengaruh yang signifikan latihan push-up terhadap kekuatan otot lengan pada atlet penahan perpani Kabupaten Banjar. 2).Ada pengaruh yang signifikan latihan pull-up terhadap kekuatan otot lengan pada atlet penahan perpani Kabupaten Banjar. 3) Ada perbedaan pengaruh yang signifikan latihan push-up dan pull-up terhadap kekuatan otot lengan pada atlet penahan perpani Kabupaten Banjar secara.

\section{Saran}

Setelah mengetahui hasil hipotesis, pembahasan serta kesimpulan dalam penelitian ini, maka penulis mengajukan saran-saran sebagai berikut :

1. Kepada Pengurus Cabang Olahraga Panahan, pelatih, pembina dan atlet panahan didalam menyusun program latihan, sebaiknya memperhatikan komponen fisik. Sebagai upaya peningkatan kemampuan kekuatan otot lengan dalam memanah dapat menggunakan metode latihan push-up dan pull-up.

2. Kepada para pelatih cabang olahraga panahan agar menerapkan metode latihan pull-up untuk meningkatkan kekuatan otot lengan dalam menarik beratnya tali busur.

3. Kepada para atlet cabang olahara panahan melaksanakan latihan secara sungguh- sungguh untuk menjaga segala unsur kondisi fisik yang dibutuhkan dalam melakukan olahraga panahan, serta melatih teknik-teknik panahan

4. Diharapkan agar penelitian ini bermanfaat sebagai bahan masukan dalam menyusun strategi program latihan cabang olahraga panahan yang mampu meningkatkan hasil memanah.

\section{REFERENSI}

Ambarukmi, Dwi H. 2007,dkk. Pelatihan Pelatih Fisik Level 1. Jakarta: Kementerian Negara Pemuda dan Olahraga Republik Indonesia. 
Artanayasa, I Wayan, 2014, Panahan., Yogyakarta : Graha Ilmu.

Aryana, Gede, 2012/2013, Pengaruh Pelatihan Push-up Terhadap Peningkatan Kekuatan Menarik dan Mendorong Otot Lengan. Jurusan Ilmu Keolahragaan, Fakultas Olahraga dan Kesehatan, Universitas Pendidikan Ganesha, Singaraja Udayana Singaraja - Bali

Barret, Jean A. 1990. Olahraga Panahan, Pedoman, Teknik dan Analisa. Semarang : Dahara Prize.

Bompa, Tudor O., Theory and Methodology of Training, The Key to Athletic Performance, Harrisburg: HumanKinetics, 2009.

Brett Stewart, 2009. 7 weeks to 50 Pull-ups. Published in the United States byUlysses PressBerkeley, CA.

Cahyono, Febriyan Dwi,dkk, 2018. Pengaruh Latihan Traditional Push Up, Plyometric Push Up, Dan Incline Push Up Terhadap Kekuatan Otot Lengan, Power Otot Lengan, Dan Daya Tahan Otot Lengan. Jurnal SPORTIF: Jurnal Penelitian Pembelajaran, Volume 4 Nomor 1 Tahun 2018. http://ojs.unpkediri.ac.id/index.php/pjk.

Chan, Faizal, 2012, Strength Training (Latihan Kekuatan). Jurnal Cerdas Sifa, Edisi No.1. Mei - Agustus 2012.

Furqon, 2001. Statistik Terapan untuk Penelitian. Bandung : Alphabeta

http://ojs.unpkediri.ac.id/index.php/pjk, Posisi push up, , diakses pada tanggal 18 September 2018.

JPOK FKIP UNLAM. 2014. Pedoman Penulisan Karya Ilmiah. Banjarbaru: Jurusan Pendidikan Olahraga dan Kesehatan Fakultas Keguruan dan Ilmu Pendidikan Universitas Lambung Mangkurat

Kamus olahraga, A \& C Black 2006 : Publishers-Dictionary of Sports and Exercise Science (2006).

Kencana, Tri Praja, 2015, Pengaruh Pelatihan Dengan Pemberian Beban Push-up Terhadap Hasil Belajar Tolak Peluru SMP Sapta Andika Denpasar. e-Journal Program Pascasarjana Universitas Pendidikan Ganesha Program Studi Penelitian dan Evaluasi Pendidikan (Volume 5, No 1 Tahun 2015).

Muhyi Faruq, dkk, 2014. Tes dan Pengukuran dalam OlahragaYogyakarta.. CV. Andi Offset.

Muluk, Dangsina, dkk. 2011, Melatih Fisik. Pengantar Teori dan Metodologi. Bandung : Lubuk Agung.

Munawar,ddk, 2014. Prediksi Prestasi Panahan Ronde Nasional Berdasarkan Daya Tahan Otot Lengan, Ketajaman Penglihatan, dan kecemasan pada Atlet PLP Panahan Jawa Tengah. Jurnal Sport Sciene 2014

Mustaqim, Enjang Ahmad, 2018, Pengaruh Latihan Push Up dan Pull Up Terhadap Hasil Flying Shoot Dalam Permainan Bola Tangan Pada Mahasiswa Komunitas Bola Tangan Unisma Bekasi. Jurnal GENTA MULIAVolume IX No. 1, Januari 2018

Nawir,Nukhrawi, 2011, Kontribusi Kekuatan Otot Tangan Dan Daya Tahan Otot Lengan Dengan Kemampuan Memanah Jarak 30 Meter Pada Atlet Panahan Sulawesi Selatan,Jurnal Competitor, Nomor 2 Tahun 3, Juni 2011.

Nusufi, Maimun, 2016. Kontribusi Daya Tahan Otot Lengan Dan Panjang Lengan Dengan Ketepatan Memanah Pada Atlet Panahan Pengprov Perpani Aceh Tahun 2015. Jurnal Ilmu Keolahragaan Vol. 15 (1), Januari - Juni 2016 : 1-25.

Dipublikasikan Oleh :

UPT Publikasi dan Pengelolaan Jurnal

Universitas Islam Kalimantan Muhammad Arsyad Al-Banjari Banjarmasin 
Samsudin, 2016. Pengaruh Latihan Push Up terhadap Kemampuan Lempar Cakram pada Siswa Kelas VII SMPN 3 Woha Kabupaten Bima. Jurnal Pendidikan Olahraga, Vol. 6. No. 2, Jul-Des 2016.

Speirs, Steve, 2009. 7 Week To 100 Push Up. Published in the United States byUlysses Press.

Sugiyono, A. 2014. Metode Penelitian Campuran (Mix Method) Jakarta : Penerbit Alphabeta

Suharjana, latihan Beban, Sebuah Metode Latihan Kekuatan. Dosen Jurusan Pendidikan Kesehatan dan Rekreasi, FIK UNY

Sukadiyanto, 2011, dkk. Melatih Fisik. Pengantar Teori dan Metodologi.Bandung.Lubuk Agung.

Susanto, 2015, Pengaruh Latihan Sirkuit Terhadap Peningkatan Kebugaran Jasmani Dan Ketepatan Membidik Panahan Pada Anak Usia Dini. Jurnal TA’ALLUM, Vol. 03, No. 02, November 2015

Winarno,M.E., 1994/1995, Belajar Motorik. Departemen Pendidikan dan Kebudayaan, Institut Keguruan Dan Ilmu Pendidikan Malang.

Yenni, Fitri Rahma, dkk, 2012, Exercise Effect Push Up Onof Distance Of 30 Meters Athlete Archery Divicion Son PPLM Bow Standart. Jurnal Pendidikan Kepelatihan Olahraga Fakultas Keguruan dan Ilmu Pendidikan Universitas Riau

Dipublikasikan Oleh: 